\title{
渦核内の高速火炎伝ぱ特性*
}

\author{
安里勝 雄 ${ }^{* 1}$, 竹内 秀 隆*2, 和 田英忠*3
}

\section{Characteristics of Rapid Flame Propagation in a Vortex Core}

\author{
Katsuo ASATO, Yoshitaka TAKEUCHI and Hidetada WADA
}

\begin{abstract}
Characteristics of flame propagation in a vortex core were experimentally investigated using a vortex ring generated by a jet of a mixture ejected through a circular nozzle. The ratio of increase in the flame speed to the maximum tangential velocity $V_{\theta \max }$ decreases gradually with increasing $V_{\theta \max }$. This is because the radius of curvature of the flame tip in the vortex core decreases with increasing $V_{\theta \max }$. The flame speed increases with increasing ratio of the densities of the unburned gas to the burned gas $\left(\rho_{u} / \rho_{b}\right)^{1 / 2}$. This is because the radius of curvature of the flame tip increases with increasing $\left(\rho_{u} / \rho_{b}\right)^{1 / 2}$. The flame speed in the vortex core can be predicted well using the model of flame propagation in which the shape of the flame tip in the vortex core is considered.
\end{abstract}

Key Words: Premixed Combustion, Vortex Core, Rotating Flow, Flame Speed, Flame Propagation

\section{1. ま え がき}

火炎構造, 火炎伝ぱ, 火炎の安定化および消炎に及 ほすす流れの場の効果は, 複雑である。これまで, 伸長 された流れ場が火炎の安定化や消炎に及ぼす効果につ いての研究が数多くなされてきているが(1)(2), 近年, 乱流燃焼と関連して渦流中での火炎の挙動が注目さ れ，それに関連する実験や理論的研究が行われるよう になった(3)〜(10).

McCormack ら ${ }^{(3)}$ は，オリフィスからピストンで押 し出されたときに形成される渦輪中では, 火炎速度が 著しく増大し, 層流燃焼速度の約 35 倍にも達するこ とを見いだしている。この現象に対する理論的裏付け は, Chomiak $^{(4)}$ にって与えられ, 乱流燃焼速度のモ デルの一つとして知られている. また, 乱流の直接数 值計算(DNS)によって, 乱流混合層は散逸を伴わな い多くの渦管によって構成されていることが明らかに なっている(11).このような乱流中での燃焼過程を理 解するためには, 渦核内での火炎伝ぱ特性を解明する

\footnotetext{
* 原稿受付 1996 年 4 月 2 日.

*1 正員, 岐皁大学工学部 (画 501-11 岐皁市柳戸 1-1)

*2 正員, (株) 豊田自動織機製作所 (画 474 大府市共和町茶屋 8)。

*3 学生員, 岐皁大学大学院.
}

ことが重要である，渦核中での高速火炎伝ぱのメカ二 ズムは, 火花点火機関内の燃焼モデルとしても採用さ れている(12)(13).さらに, Ishizuka ${ }^{(14)(15)}$ は, 回転流中 での火炎伝ぱの挙動を調べ, Chomiak の理論の妥当 性および火炎伝ぱに及ぼすルイス数の効果を検討して いる. McManus と Bowman ${ }^{(16)}$ は, 三角翼形ボルテ ックスジェネレータの下流に形成される渦流を制御す ることによって, 最大 $75 \%$ の熱発生速度の増大を達成 している.

このように, 渦流中での火炎伝ぱの挙動は, 乱流燃 焼や内燃機関内の燃焼モデルとして重要であると同時 に，高負荷燃焼や希薄燃焼の可能性と関連して，燃焼 学的に極めて興味深い問題である．しかしながら，渦 核中での火炎伝ぱを詳細に調べた研究は少なく，渦核 中での火炎伝ぱ機構についての詳細もよく知られてい ない. 本研究では, 安定でかつ流体力学的特性がよく 知られている渦輪を用い, 洞核内の火炎伝ぱ特性を調 べ, 渦核中での火炎伝ば機構について検討を加えた。

\section{2. 実験装置および方法}

図 1 は本研究で用いた渦輪発生装置および渦輪の概 略を示す.シリンダ 1 および 2 は, 内径 $220 \mathrm{~mm}$, 長 さが，それぞれ 355 および $325 \mathrm{~mm}$ である.シリンダ 
2 の先端には, 直径 $D_{0}$ のノズルが取付けられている. 圧縮空気は減圧弁で調圧され, 電磁弁によってシリン ダ 1 に瞬間的に供給される. 圧縮空気によって駆動さ れたピストン 1 は, 連結されているシリンダ 2 のピス トン 2 を駆動する.ピストン 2 の移動によりシリンダ 2 に供給されている未燃混合気は，ノズルから大気中 に噴出され，図 1 に示すようなドーナツ状の渦輪がノ ズル下流に形成される、ノズルから噴出された渦輪が 周囲大気によって希釈されるのを防ぐために，ノズル 外壁部には，円筒フードが取付けられている．この円 筒フード内部にも, シリンダ 2 内に供給されている混 合気と同じ組成の混合気を充てんして，実験は行われ た. 渦輪は, 移動速度 $U$, 直径 $D$ で下流方向に移動 する，渦の強さは，ピストンの移動速度，ストローク およびノズル直径を調整することによって変化させる ことができる，渦輪の移動速度および直径は, 線香の 煙を用いた可視化法によって測定された。

図 2 は, 渦輪中の火炎伝ぱの挙動を観察するための, 高速度影写真撮影装置を示す。渦輪発生装置から噴出 された渦輪は,ノズルの下流 $X=30 \mathrm{~cm}$ の位置に設置 された火花点火装置により点火される。渦輪内の火炎 伝ぱの様子は，渦輪発生装置および火花点火装置と同 期された高速度ビデオカメラにより, 毎秒約 $4500 こ$ まの高速度影写真撮影を行うことによって，観察され

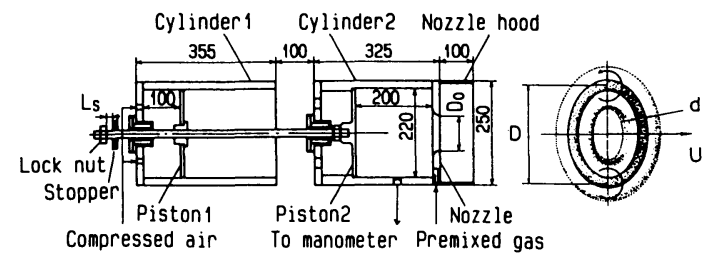

Fig. 1 Vortex ring generator and sketch of vortex ring

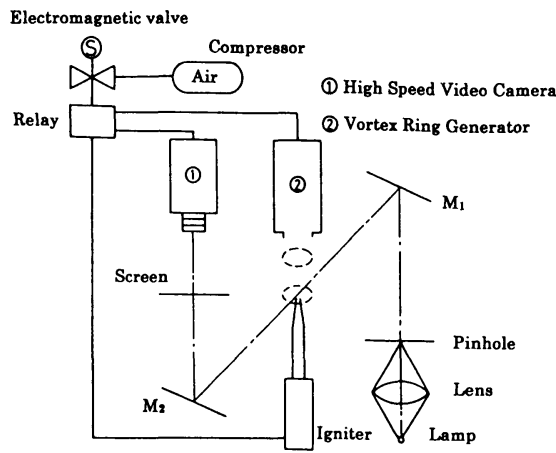

Fig. 2 Layout of experimental apparatus
た。

\section{3. 実験結果および考察}

\section{$3 \cdot 1$ 渦輪の移動速度, 直径および最大周速度}

図 3 はノズル下流 $30 \mathrm{~cm}$ の位置における, 渦輪の移動 速度および直径を示す。横軸は，ピストン 1 へ供給さ れる圧縮空気の供給圧力 $P_{s}$ を示し, 綐軸は移動速度 $U$ および渦輪の無次元直径 $D / D_{0}$ を示す。供給圧力 の増加とともに, 移動速度は増加する. ノズル径 $D_{0}$ が小さく, ピストンストローク $L_{s}$ が大きいほど, 移 動速度は速い。一方， $L_{s}$ が大きく， $D_{0}$ が小さくなる ほど, 渦輪の無次元直径は大きくなるが, 供給圧力に 無関係にほぼ定の值を示す。このような渦輪の流体 力学的特性は, Maxworthyによっても報告されてい $る^{(17)(18)}$

$\mathrm{Lamb}^{(19)}$ の理論によると, 渦輪の移動速度 $U$ は,

$$
U=\frac{\Gamma}{2 \pi D}\left(\ln \frac{8 D}{d}-\frac{1}{4}\right)
$$

で与えられる。ここで $\Gamma$ おび $d$ は, 循環および渦 核直径を示す。一般的に渦核直径は, 渦輪直径の約 $10 \%$ とされている(20). したがって，本実験においても 渦輪直径の $10 \%$ 渦核直径と仮定すると, 実験で求め た移動速度および渦輪直径を用いて，式（1）から渦輪

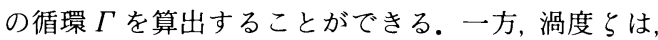
円筒座標を用いて表すと,

$$
\zeta=\frac{1}{r} \frac{\partial\left(r V_{\theta}\right)}{\partial r}-\frac{1}{r} \frac{\partial V_{r}}{\partial \theta}
$$

となる，ここで $r, V_{\theta}$ および $V_{r}$ は，渦核の半径方向 距離, 周方向速度成分および半径方向速度成分を示 寸．渦核内では，半径方向の速度成分 $V_{r}$ は存在しな いので式(2)は,

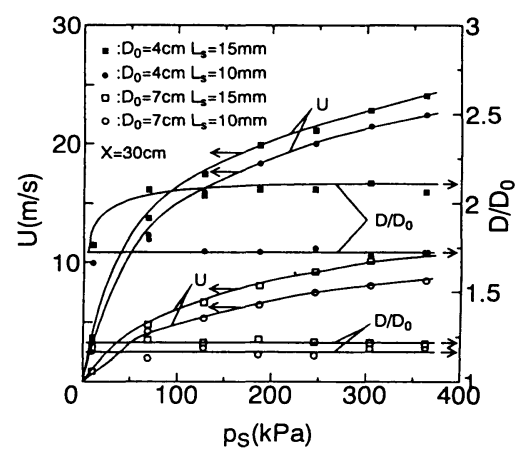

Fig. 3 Forward velocity and diameter of vortex ring 


$$
\zeta=\frac{V_{0}}{r}+\frac{d V_{\theta}}{d r}
$$

となる. 右辺第 2 項 $d V_{\theta} / d_{r}$ は角速度 $\omega$ を表し, 渦度 との関係は， $\omega=\zeta / 2$ でちられる。㟠核を剛体渦と 仮定すると, 渦核半径 $r=a=d / 2$ において, 周速度 は最大になるので, 最大周速度 $V_{\theta \max }$ は, 式( 3 )よ ,

$$
V_{\theta \max }=\frac{\zeta a}{2}
$$

となる。一方, 循環 $\Gamma$ と渦度 $\zeta$ の関係は, $\Gamma=\pi a^{2} \zeta$ で与えられ，この関係と式 (1) および式 (4)から,

$$
V_{\theta \max }=\frac{\Gamma}{2 \pi a}=\frac{2}{\left(\ln \frac{8 D}{d}-\frac{1}{4}\right)} \frac{D}{d} U
$$

となる. 渦輪の移動速度 $U$ と直径 $D$ から, 式 $(5)$ を 用い, 渦核の最大周速度を求めることができる.

図 4 は, 供給圧力と最大周速度 $V_{\theta \max }$ の関係を示 す. 供給压力の増加とともに， $V_{\theta \max }$ は増加し，また， $L_{s}$ が大きく, $D_{0}$ が小さいほど, $V_{\theta \max }$ は大きくなる.

\section{$3 \cdot 2$ 渦核内の火炎速度図 5 は, 高速度力メ}

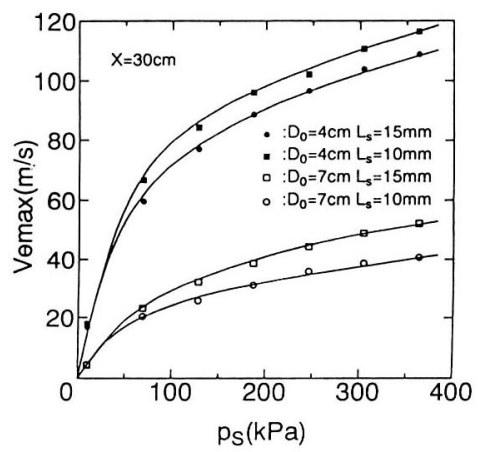

Fig. 4 Maximum tangential velocity in the vortex core

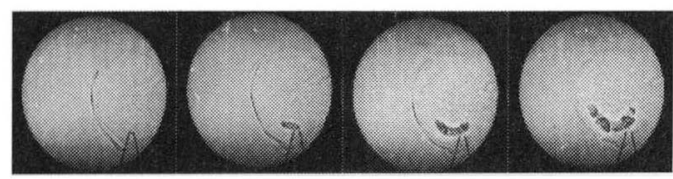

$\begin{array}{llll}\text { (a) } 0 \mathrm{~ms} & \text { (b) } 2.1 \mathrm{~ms} & \text { (c) } 4.2 \mathrm{~ms} & \text { (d) } 5.9 \mathrm{~ms}\end{array}$

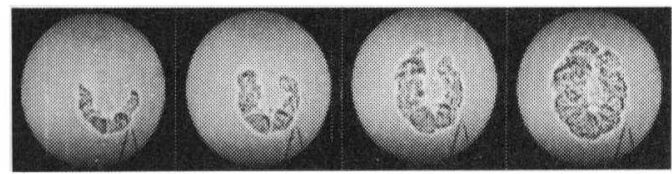

$\begin{array}{llll}\text { (e) } 7.6 \mathrm{~ms} & \text { (f) } 9.3 \mathrm{~ms} & \text { (g) } 11 \mathrm{~ms} & \text { (h) } 12.3 \mathrm{~ms}\end{array}$

Fig. 5 Examples of high ${ }^{-}$speed shadowgraph of flame propagation
で撮影した渦輪内の火炎伝ぱの影写真の一例を示す。 図 5 (a) は, 火花電極により渦輪の渦核部分に着火さ れた瞬間であり，電極付近に火炎核が形成されている 様子がわかる。 その後, 火炎は, 時間経過とともに渦 核に沿うように双手にわかれ，弧を描きながら両方向 に伝ぱし, 図 5 (h)において二つの火炎は出会い, 燃 焼を終了する。火炎は図 5(e)のように先端の尖った 形をしながら渦核上を伝ぱし, その後, 周囲の渦領域 へ燃焼が進む。また，火炎面にはセル状の乱れが見ら れる(21).このような写真から, 渦核中を伝ぱする火炎 の火炎速度が求められる.

図 6，7は,メタン-空気混合気およびプロパンー空

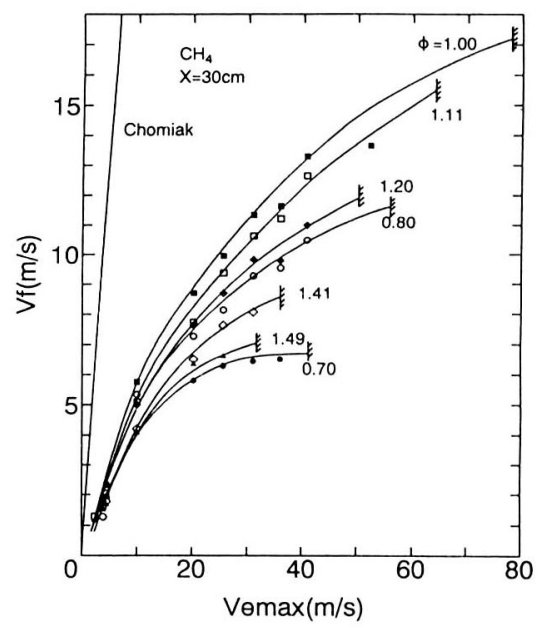

Fig. 6 Ralationship between flame speed and maximum tangential velocity (Methane-air mixture)

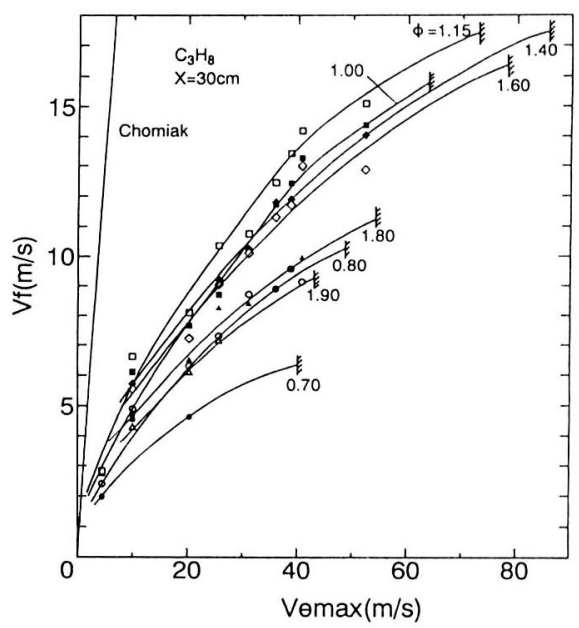

Fig. 7 Relationship between flame speed and maximum tangential velocity (Propane-air mixture) 
気混合気の最大周速度 $V_{\theta \max }$ に対する火炎速度 $V_{f}$ の 変化を示す。図中のハッチングは, 渦核内を伝ぱする 火炎の消炎限界を示す(22). いずれの混合気において も， $V_{\theta \max }$ の増加とともに, $V_{f}$ は増加する.しかし, $V_{\theta \max }$ に対する $V_{f}$ の増加割合は, $V_{\theta \max }$ の増加ととも に減少していく.メタン-空気混合気の場合, 当量比 $\phi=1.0$ で, プロパン-空気混合気の場合, 当量比 $\phi=$ 1.15 で, 最大の $V_{f}$ の值を示し, これより希薄側およ び過濃側へ行くにつれて, $V_{f}$ は減少する. 図 6,7 に示すように, 渦核中で, 火炎は高速で伝ぱするが, このような渦核中での高速火炎伝ぱのメカニズムは, Chomiak $^{(4)}$ によって提案されている。回転流中での 未燃ガスと燃焼ガスの密度差に基づく圧力低下の差 が, 火炎を燃焼ガス側から未燃ガス側に駆動し, 火炎 が末燃ガスの渦核中に引き込まれ，「伝ぱ」する現象 が生ずる. 燃焼速度が, 化学反応速度や物質および熱 の輸送係数に律せられるのに対し, 渦核中での火炎伝 ぱは, 流体力学的な機構に律せられている.渦核中で の理論火炎速度 $V_{f \mathrm{th}}$ は, Chomiakによって次式で与 えられる(4).

$$
V_{f \mathrm{th}}=\left(\rho_{u} / \rho_{b}\right)^{1 / 2} V_{\theta \max }
$$

ここで， $\rho_{u}$ および $\rho_{b}$ は，それぞれ未燃ガスおよび燃 焼ガスの密度を示す. 図 6,7 に, 当量比 $\phi=1.0$ およ び 1.15 に対する式( 6 )から算出した理論火炎速度 $V_{f \mathrm{th}}$ を実線で示してある. Chomiak の理論結果は, 実験結果と定性的に一致するが, 定量的に大きな違い がある。

図 8 は, 最大周速度 $V_{\theta \max }$ を一定にした場合の火炎 速度と $\left(\rho_{u} / \rho_{b}\right)^{1 / 2}$ との関係を示す. 図中の破線および 鎖線については, 後に述べる.また, 戝の上部には, Chomiak の理論結果も示してある.いずれの混合気 においても, 火炎速度は, $\left(\rho_{u} / \rho_{b}\right)^{1 / 2}$ に比例して増加 する.しかし, Chomiak の理論結果は, 実験結果より

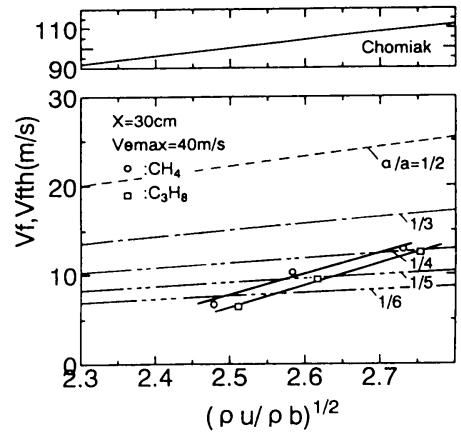

Fig. 8 Relationship between flame speed and $\left(\rho_{u} / \rho_{b}\right)^{1 / 2}$
かなり高い值を示している.

小野らは, 希薄混合気で形成した剛体渦の中心で着 火した場合, 角速度が速くなるにつれて火炎が伝ぱで きる半径方向距離が短くなり, やがてある一定の半径 で消炎してしまうことを見いだしている(23). また，

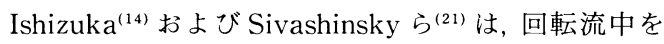
伝ぱする火炎の場合, 角速度が速いほど, 火炎先端は 尖った形になることを見いだしている. Chomiakの 理論では, 渦核中を伝ぱする火炎の火炎速度を算出す る際，火炎先端の形状は考慮されてない.このことが 図 6, 7 および図 8 に示すように, Chomiak の理論結 果が実験結果と定量的に大きく異なる原因と思われ る.したがって, 渦核内を伝ぱする火炎の伝ぱモデル を考える場合, 火炎先端の形状を考慮する必要がある と思われる。

\section{$3 \cdot 3$ 火资先端形状を考慮した火资伝ぱモデル}

図 9 は, 火炎先端の形状を考慮した場合の火炎伝ぱモ デルを示す。一定の角速度 $\omega$ で回転し, 回転軸方向の 速度成分をもたない渦管を考える。一般に，このよう な渦管の速度分布は, 図 9 (a)に示されるようなラン キンの組合せ渦の形をしていると考えられ，渦核内は 剛体回転をしている.このような場での半径方向の圧 力こう配は,

$$
\frac{d p}{d r}=\rho-\frac{V_{\theta}^{2}}{r}
$$

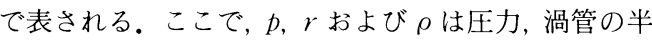
径方向距離および密度を示す。渦核半径を $a$ とする と, 周速度 $V_{\theta}$ は,

$$
V_{\theta}=\omega r \quad(r \leqq a)
$$

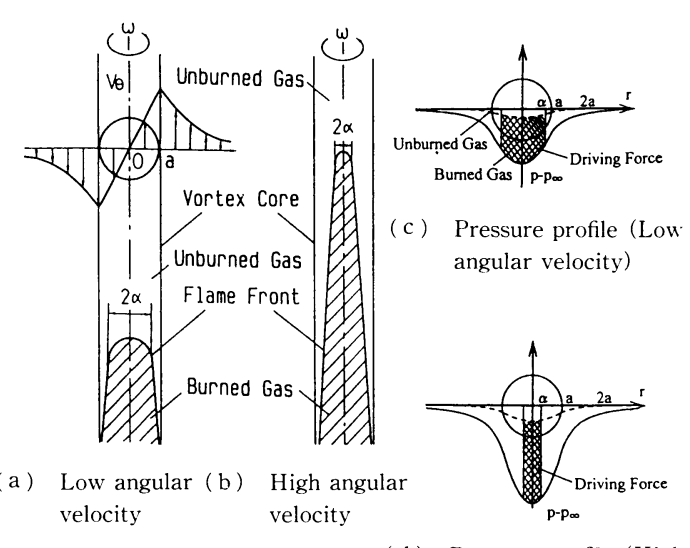

(d) Pressure profile (High angular velocity)

Fig. 9 Model of flame propagation 


$$
V_{\theta}=\frac{a^{2} \omega}{r} \quad(r>a)
$$

となる. 式 $(8)$ をもとに式 $(7)$ を解くと, 渦領域にお ける圧力は,

末燃ガス領域;

$$
\begin{aligned}
& p_{u}=p_{\infty}-\rho_{u} \omega^{2} a^{2}+\frac{1}{2} \rho_{u} \omega^{2} r^{2} \quad(r \leqq a) \cdots \cdots(9 \cdot \mathrm{a}) \\
& p_{u}=p_{\infty}-\frac{1}{2} \frac{\rho_{u} \omega^{2} a^{4}}{r^{2}} \quad(r>a) \cdots \cdots \cdots \cdots \cdots(9 \cdot \mathrm{b})
\end{aligned}
$$

燃焼ガス領域;

$$
\begin{aligned}
& p_{b}=p_{\infty}-\rho_{b} \omega^{2} a^{2}+\frac{1}{2} \rho_{b} \omega^{2} r^{2} \quad(r \leqq a) \cdots(10 \cdot \mathrm{a}) \\
& p_{b}=p_{\infty}-\frac{1}{2} \frac{\rho_{b} \omega^{2} a^{4}}{r^{2}} \quad(r>a) \cdots \cdots \cdots \cdots \cdots(10 \cdot \mathrm{b})
\end{aligned}
$$

となる。ここで, $p_{\infty}$ は周囲大気压を示し, 添字いお よび $b$ は，末燃ガスおよび燃焼ガスを意味する。

図 6 〜 に示す実験結果を定量的に予測するため に，小野ら ${ }^{(23)}$ および Ishizuka ${ }^{(14)}$ の実験結果をもとに, 渦核内での火炎の半径方向への広がりを考慮した火炎 伝ぱモデルを考える。今，渦核内での火炎は， $V_{\theta \max }$ の増加とともに半径方向への広がりが抑えられ，渦核 内の限られた領域にしか存在しないとする。このよう に考えると、 $V_{\theta \max }$ が小さい場合, 図 9 (a)に示すよ うに, 渦核内の火炎先端の曲率半径は大きく, 図 9 （c）に示す網かけ部分の圧力差が，火炎を末燃ガス側 へ駆動する力となる。一方, $V_{\theta \max }$ の増加とともに, 図 9 (b)に示すように, 渦核内の火炎先端が尖り, 曲 率半径が小さくなり, その結果, 図 $9(\mathrm{~d})$ に示すよう に, 火炎を未燃ガス側へと駆動する圧力差が作用する 領域が狭くなる。すなわち, 図 9 ( c ), (d)に, 網か けで示す領域の平均圧力が火炎を未燃がス側へ駆動す る力となる。このときの未燃ガス領域および燃焼がス

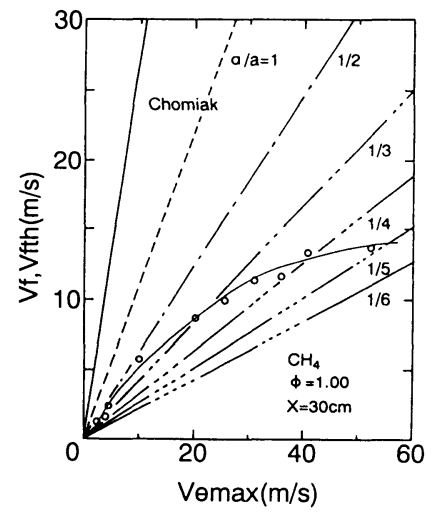

Fig. 10 Change of flame speed with maximum tangential velocity (Methane-air mixture)
領域における平均圧力 $\bar{p}_{u}$ および $\bar{p}_{b}$ は,

$$
\begin{aligned}
& \bar{p}_{u}=\frac{1}{\pi(2 a)^{2}}\left(\int_{0}^{2 a} p_{u} \cdot 2 \pi r \cdot d r\right) \cdots \cdots \cdots \cdot(11 \cdot \mathrm{a}) \\
& \bar{p}_{b}=\frac{1}{\pi(2 a)^{2}}\left(\int_{0}^{\alpha} p_{b} \cdot 2 \pi r \cdot d r+\int_{a}^{2 a} p_{u} \cdot 2 \pi r \cdot d r\right)
\end{aligned}
$$

で与えられる。ここで， $\alpha$ は渦核内を火炎が伝ぱしう る半径方向距離を示す。また, 式(11) は, 渦核半径の 2 倍の領域 $(-2 a \leqq r \leqq 2 a)$ にかかる平均圧力を示す. 渦核半径の 2 倍の領域にかかる平均圧力をとった理由 は, $V_{\theta \max }$ の小さい領域での火炎先端の曲率半径が渦 核半径の 2 倍程度であること,そして, 渦核半径の 2 倍の位置での未燃ガスと燃焼ガスの圧力差が非常に小 さくなっていることによる. 式(11)で示した未燃ガス 領域と燃焼ガス領域での平均圧力の差が,この場合の 火炎を高速で伝ぱさせる駆動力となる。したがって, 渦核中を伝ぱする火炎の理論火炎速度 $V_{f \mathrm{th}}$ は,

$$
\int_{A}\left(\bar{p}_{b}-\bar{p}_{u}\right) \cdot d A=\int_{A} \rho_{b} V_{f \mathrm{th}}^{2} d A
$$

となる.ここで, $d A$ は渦領域内の微小面積を示す。 式(10) （12）から, 渦核内の火炎先端の形状を考慮し た理論火炎速度 $V_{f \mathrm{th}}$ は,

$$
V_{f \mathrm{th}}=\frac{\alpha}{2 a} V_{\theta \max } \sqrt{\left(\frac{\rho_{u}}{\rho_{b}}-1\right)\left(1-\frac{\alpha^{2}}{4 a^{2}}\right)}
$$

となる.式(13)を用いて算出した理論火炎速度 $V_{f \mathrm{th}}$ の一例を図 10,11 に, 破線㧍よび鎖線で示す，図中の おのおのの線は, 渦核半径に対する火炎先端の曲率半 径の比 $\alpha / a$ の値が, $\alpha / a=1,1 / 2,1 / 3,1 / 4,1 / 5,1 / 6$ と した場合の理論火炎速度 $V_{f \mathrm{th}}$ を示す。得られた理論 火炎速度 $V_{f \mathrm{th}}$ は, $\mathrm{V}_{\theta \max }$ に比例して増加するが, $\alpha / a$ の減少とともに，すなわち火炎先端が細くなるととも に, $V_{\theta \max }$ に対する $V_{f \mathrm{th}}$ の増加割合は小さくなる。一

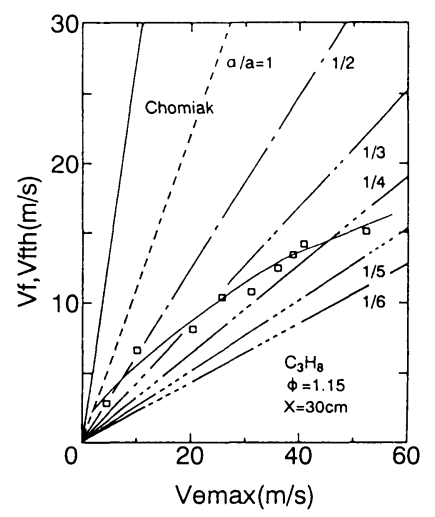

Fig. 11 Change of flame speed with maximum tangential velocity (Propane-air mixture) 
方, 実験で求めた火炎速度 $V_{f}$ の増加割合は, $V_{\theta \max }$ の 増加とともに, 小さくなっている.これは, 図 10,11 中の破線および鎖線が示すように， $V_{\theta \max }$ の増加とと もに $\alpha / a$ の值が小さくなり,すなわち, 火炎先端が細 くなり, 火炎伝ぱの駆動力となる末燃ガス領域と燃焼 ガス領域での圧力差が小さくなってくるためと考えら れる。

図 8 には， $V_{\theta \max }$ を一定とした場合の式(13)を用い て算出した理論火炎速度 $V_{f \mathrm{th}}$ を, 破線および鎖線で 示す. $V_{f \mathrm{th}}$ は, $\left(\rho_{u} / \rho_{b}\right)^{1 / 2}$ および $\alpha / a$ の増加とともに 増加する。 また, $V_{f \mathrm{th}}$ は, Chomiakによって指摘さ れているように, $\left(\rho_{u} / \rho_{b}\right)^{1 / 2}$ に比例して増加する. $\left(\rho_{u} / \rho_{b}\right)^{1 / 2}$ の増加とともに, $V_{f}$ の実験值は, $\alpha / a=1 / 6$ から約 $1 / 4$ まで変化している.このことは, $\left(\rho_{u}\right)$ $\left.\rho_{b}\right)^{1 / 2}$ の増加とともに, すなわち当量比が 1.0 に近づ くにつれて, 火炎が伝ぱしうる渦核内の半径方向距離 が大きくなる,すなわち, 火炎先端の曲率半径が大き くなることを意味している。このように, 渦核内を伝 ぱする火炎の先端形状を考慮した火炎伝ぱモデルは, 実験結果(図 $8,10,11$ )を定性的にも, 定量的にもよ く説明することができる.

\section{4. 結言}

本研究では, 渦輪の流体力学的特性および渦輪内で の火炎伝ば特性を調べ, 渦核中での火炎伝ぱ機構に対 する検討を行った。得られた結果は次のとおりであ る.

（1）渦核中を伝ぱする火炎の火炎速度は, 渦輪の 移動速度, 直径および渦核の大きさによって决まる渦 輪内の最大周速度とともに増加する。しかし, 最大周 速度に対する火炎速度の増加割合は, 最大周速度の増 加とともに減少する。これは, 最大周速度の増加とと もに, 渦核内を伝ぱする火炎先端の曲率半径が小さく なることに起因する.

（2）渦核内の最大周速度が一定の場合, 火炎速度 は, $\left(\rho_{u} / \rho_{b}\right)^{1 / 2}$ に比例して増加する。これは, $\left(\rho_{u} /\right.$ $\left.\rho_{b}\right)^{1 / 2}$ の増加とともに, 渦核内の火炎先端の曲率半径 が大きくなることに起因する.

（3）渦核内を伝ぱする火炎の火炎速度を定量的に 予測するためには, 渦核内を伝ぱする火炎先端の形状
を考慮した火炎伝ぱモデルを用いることが必要であ る.

本研究の一部は, 文部省科学研究費 (課題番号 06650239)の助成によって行われた。ここに記して謝 意を表す。

\section{文献}

(1) Tsuji, H. らの一連の研究, 例えば, Tsuji, H., Proc. ASME-JSME Thermal Eng. Joint Conf., 4(1983), 1119.

(2) Law, C. K., 22nd Symp. (Int.) on Combust., (1988), 1381-1402, The Combust. Inst.

(3) McCormack, P. D., ほか3名, Combust. Flame, 19 (1972), 297-303.

(4) Chomiak, J., 16th Symp. (Int.) on Combust., (1976), 1665-1672, The Combust. Inst. .

(5) Peters, N. and Williams, F. A., 22nd Symp. (Int.) on Combust., (1988), 495-503, The Combust. Inst. .

(6) Jarosinski, J., ほか2名, 22nd Symp. (Int.) on Combust., (1988), 505-514, The Combust. Inst.

( 7 ) Gutmark, E., ほか 3 名, 22nd Symp. (Int.) on Combust., (1988), 523-529, The Combust. Inst.

(8) Gary Yip, T. W., ほか 2 名, 20th Symp. (Int.) on Combust., (1984), 1655-1662. The Combust. Inst. .

(9) Cattolica, R. J. and Vosen, S. R., Combust. Sci. Tehnol., 48(1986), 77-87.

(10) Hasegawa, T., ほか 2 名, Combust. Sci. Tech., 108 (1995), 67-80.

(11) Vincent, A. and Meneguzzi, W., J. Fluid Mech., 258 (1994), 245-254.

(12) Tabaczynski, R. J., ほか 2 名, Combust. and Flame, 39 (1980), 111-121.

(13) Daneshyar, H. and Hill, P. G., Prog. of Energy and Combust. Sci., 13(1987), 47-73.

(14) Ishizuka, S., Combust. Flame, 82(1990), 176-190.

（15）石塚悟 - 平野敏右, 燃焼の科学と技術, 2(1994)，15-26.

(16) McManus, K. R., and Bowman, C. T., 23rd Symp. (Int.) on Combust., (1990), 1093-1099, The Combust. Inst. .

(17) Maxworthy, T., J. Fluid Mech., 51-1(1972), 15-32.

(18) Maxworthy, T., J. Fluid Mech., 81-3(1977), 465-495.

(19) Lamb, H., Hydrodyanamics, 6th ed., (1945), 241-246, Dover.

(20) Johnson, G. M., Aero. Res. Lab., Wright-Patterson A. F. B., Rep. ARL70-0093, (1970), 1-43.

(21) Sivashinsky, G. I., ほか 3 名. Combust. Sci. Technol., 57 (1988), 37-53.

(22) Asato, K. and Wada, H., Proc. of 8th Transport Phenomena in Combustion, (1996), (in press).

(23) Ono, S., ほか 4 名, Proc. of 2nd JSME-KSME thermal eng. conf., 1 (1992), 207-212. 